\title{
Human exposure to RF radiation in Sri Lanka
}

\author{
M. A. A. Karunarathna and I. J. Dayawana* \\ Department of Electronic and Telecommunication, University of Moratuwa, Moratuwa, 10400, Sri Lanka
}

\begin{abstract}
This paper presents the exposure levels of major cities in Sri Lanka due to the different RF emitters. As the RF emitters, the transmitting antennas of FM radio, TV and Cellular Mobile Base stations were considered. Field strength measurements were made at several locations in big cities and the exposure levels were obtained using a dipole antenna mounted $1.4 \mathrm{~m}$ above the ground level to consider the exposure to RF radiation by the general public. The results were compared with the internationally recognized FCC standards and the present exposure levels were found to be well below the maximum limits set by the standards. The percentage distribution of electromagnetic field radiated from FM radio, TV and Cellular Mobile services for different environments are also presented. In addition, the unsafe distances to live from different transmitting antennas are presented.
\end{abstract}

\section{INTRODUCTION}

It has been known for some time that high intensities of RF radiation can be harmful due to the ability of RF energy to heat biological tissue rapidly ${ }^{1}$. Tissue damage can be due to the body's inability to cope with or dissipate the excessive heat. Under certain conditions, exposure to RF radiation with power densities of approximately $10 \mathrm{~mW} / \mathrm{cm}^{2}$ or more could result in measurable heating of biological tissue ${ }^{2}$. The extent of heating would depend on several factors including frequency of the radiation; size, shape and orientation of the

\footnotetext{
* Corresponding Author, E-mail: indra@ent.mrt.ac.lk
} 
exposed object; duration of exposure; environmental conditions and efficiency of heat dissipation. Biological effects that result from heating of tissue by RF energy are referred to as "thermal" effects.

From a source of RF radiation, whole-body absorption of RF energy by humans will occur at a maximum rate when the frequency of the radiation is between 30 and $300 \mathrm{MHz}$. Therefore the most stringent standards are in this frequency range. Body absorption of RF radiation is due to a resonance phenomenon ${ }^{2}$ and RF safety standards take this frequency dependence into account. Safety guidelines for exposure of the public to the RF radiation from transmitting antennas are set by different organizations such as the Institute of Electrical and Electronic Engineers ${ }^{3}$ (IEEE), International Commission on Non-Ionizing Radiation Protection ${ }^{4}$ (ICNIRP), National Radiation Protection Board ${ }^{5}$ (NRPB) and The Federal Communications Commission ${ }^{2}$ (FCC).

We are mainly exposed to the electromagnetic fields radiated by transmitting antennas of FM radio broadcasting in the range $88 \mathrm{MHz}-108 \mathrm{MHz}$, Television broadcasting in the VHF and UHF and Base stations of Cellular Mobile systems operating in the $825-960$ $\mathrm{MHz}$ region ${ }^{5}$. These systems are the main sources of electromagnetic radiation (EMR) close to residential areas. According to literature ${ }^{5-8}$, these RF transmitters are causing bad effects to the people in Europe. Work is in progress at University of Moratuwa to ascertain the amount of RF radiation absorbed by the general public due to RF emitting transmitting antennas in Sri Lanka.

The transmitter coverage depends on the antenna height and the Effective Radiated Power (ERP). The FM radio and TV antennas are usually mounted on high towers and transmit relatively high powers. FCC permits a maximum ERP of $100 \mathrm{~kW}$ for FM Radio and lowband VHF television stations; $316 \mathrm{~kW}$ for high-band VHF and 5 MW for UHF television stations $^{2}$. Mobile base station antennas are mounted at a height of 15-50 m from ground level and transmit relatively low powers. FCC permits a maximum ERP of $500 \mathrm{~W}$ per channel.

The steady increase in the number of subscribers of mobile telecommunication systems is pushing towards an enhancement of the capacity of the systems themselves. As a result, more and more base stations are being installed on the rooftop of existing buildings in densely populated areas. These installations give rise to widespread concerns among the 
population regarding possible detrimental effects to human health from exposure to the electromagnetic waves radiated by these base station antennas. Therefore it is necessary to examine the exposure levels to RF radiation around these antennas to determine whether they are safe or unsafe. The safety distances, known as the compliance distances ${ }^{5}$ can also be determined with respect to the different standards.

\section{ELECTRIC FIELD INTENSITY AND POWER DENSITY}

The electric field intensity, $E$, and power density, $S$, of an electromagnetic field are two quantities whose limiting values are specified by international standards for public safety. If the maximum electric field at a particular location due to all RF sources in the environment can be obtained by measurement, then the power density, of the electromagnetic field at that location can be estimated from equation (1).

$$
S\left(\mathrm{~W} / \mathrm{m}^{2}\right)=\frac{E^{2}}{\eta}
$$

where $\eta$ is the intrinsic impedance of free space $=377 \Omega$.

The electromagnetic radiation reference levels of electric field intensity and power density as given by FCC standards ${ }^{2}$ for the general public is given in Table1. In Sri Lanka, Telecom Regulatory Commission (TRC) uses FCC standards for RF safety issues.

Table 1: Electromagnetic radiation reference levels according to FCC standards [frequency $\mathrm{f}$ in $\mathrm{MHz}$ ]

\begin{tabular}{|l|l|l|l|l|}
\hline \multirow{2}{*}{ Service } & Frequency Bands & \multicolumn{3}{|c|}{ EMR Reference level } \\
\cline { 3 - 5 } & & $\begin{array}{l}\text { Field } \\
(\mathrm{V} / \mathrm{m})\end{array}$ & Strength, E & $\begin{array}{l}\text { Power } \\
\left(\mathrm{W} / \mathrm{m}^{2}\right)\end{array}$ \\
\hline $\begin{array}{l}\text { Radio } \\
\text { (FM band) }\end{array}$ & $87.6-107.9 \mathrm{MHz}$ & & 27.5 & 2 \\
\hline $\begin{array}{l}\text { Television } \\
\text { (VHF) }\end{array}$ & $54-68 \mathrm{MHz}$ & 27.5 & 2 \\
\hline $\begin{array}{l}\text { Television } \\
\text { (UHF) }\end{array}$ & $174-230 \mathrm{MHz}$ & -- & $f / 150$ \\
\hline $\begin{array}{l}\text { Mobile Base } \\
\text { stations }\end{array}$ & $870-806 \mathrm{MHz}$ & & -- & $f / 150$ \\
\hline
\end{tabular}


If the experimental values of $E$ and $S$ are less than the safety standards specified by the accepted international organizations, then it is assumed that there is no health risk.

In order to ensure compliance with the Maximum Permissible Exposure (MPE) for the environment, a dimensionless quantity known as the exposure quotient is calculated ${ }^{3,5,8}$. This quantity is expressed in terms of the calculated power density $S$ from measured results of the field strength and the Maximum Permissible Exposure (MPE) in power density. Thus,

exposure quotient $=\frac{S}{M P E}$

For all the transmitters of FM radio, TV and Cellular Mobile Base stations, the sum of the ratios of the measured power density to the corresponding MPE of the power density should not exceed unity ${ }^{3}$ to ensure safety. That is

$$
\sum_{i=1}^{n} \frac{S_{i}}{M P E_{i}} \leq 1
$$

If this condition is not met, then the environment is not safe. It is also the usual practice to estimate how many times the present EMR level is below the safe limit ${ }^{8}$. 'Times Below Limits' abbreviated as TBL is easily obtained from equation (4) :

$$
T B L \text { for Power Density }=\frac{1}{\sum_{i=1}^{n} \frac{S_{i}}{M P E_{i}}}
$$

where,

$S_{i}$ - Power Density at the $i^{\text {th }}$ frequency, frequency given in $\mathrm{MHz}$ $M P E_{i}$ - Reference level of the Power Density at the $i^{\text {th }}$ frequency $n$ - Total number of transmitting signals 


\section{SAFE DISTANCE FROM SOURCE OF RADIATION}

The general approach to evaluate the safe distance or the compliance distance is to examine the variation of either the power density or the electric field strength or specific absorption rate (SAR) in the vicinity of the radiation source which is usually the transmitting antenna. The compliance distance is then ascertained as the distance at which the one of these factors i.e., power density, field intensity and the SAR drops to the safe values as specified by the internationally accepted standards. An effective closed surface is then defined around the antenna in order to keep the public out of this region.

For calculation of the compliance distance more accurate near-field calculations produce the lesser compliance distances than the inverse-square law calculations i.e., a higher compliance distance is obtained from inverse square law calculations. Therefore the higher restricted areas are obtained from the far field calculations. As our concern is more for the worst-case conditions, inverse square law is used to perform the calculations. In these calculations, the minor lobes of the radiation pattern of the transmitting antenna are ignored and only the main beam is considered.

The strength of the RF wave from the transmitting antenna decreases according to the inverse square law. Therefore the power density of the electromagnetic wave at a distance $d$ from the antenna can be obtained from equation ${ }^{5}(5)$.

$$
S=\frac{N P_{r a d} G}{4 \pi d^{2}}
$$

ie: $d=\sqrt{\frac{N P_{r a d} G}{4 \pi S_{r e f}}}$

where,

$N$ : Number of transmitted signals from one base station.

$P_{\text {rad }}:$ Radiated power of one transmitted signal

$G \quad$ : Gain of the antenna

$S_{\text {ref }}$ : Reference levels of power density with respect to the different standards

$d$ : Compliance distance of the antenna 
Values of $N, P_{r a d}$ and $G$ are obtained from the service operators ${ }^{9}$. The value of $S_{r e f}$ is given in the standards ${ }^{2-5}$. Then $d$ can be estimated from equation (6).

\section{OBSERVATIONS, RESULTS AND DISCUSSION}

\subsection{Field Intensity and Power Density}

RF Signal strengths at University of Moratuwa at Katubedda in Moratuwa due to cellular mobile base stations, TV stations and FM radio stations were initially measured. The measurement set up used is shown in Fig:1. It consists of an adjustable half-wave dipole antenna and a spectrum analyzer. The antenna length can be adjusted for frequencies from $30 \mathrm{MHz}$ to $1 \mathrm{GHz}$. The measurements of field intensity were made at different locations, which represents highly populated urban environment with a flat terrain, such as several places in and around Colombo. Measurements were also made along the coastal belt towards the south of the country at Ambalangoda, Galle and Matara, which are urban, and therefore densely populated areas. Kandy, Kegalla and Kurunegala are hilly areas at high elevation and measurements were taken from these areas as well.

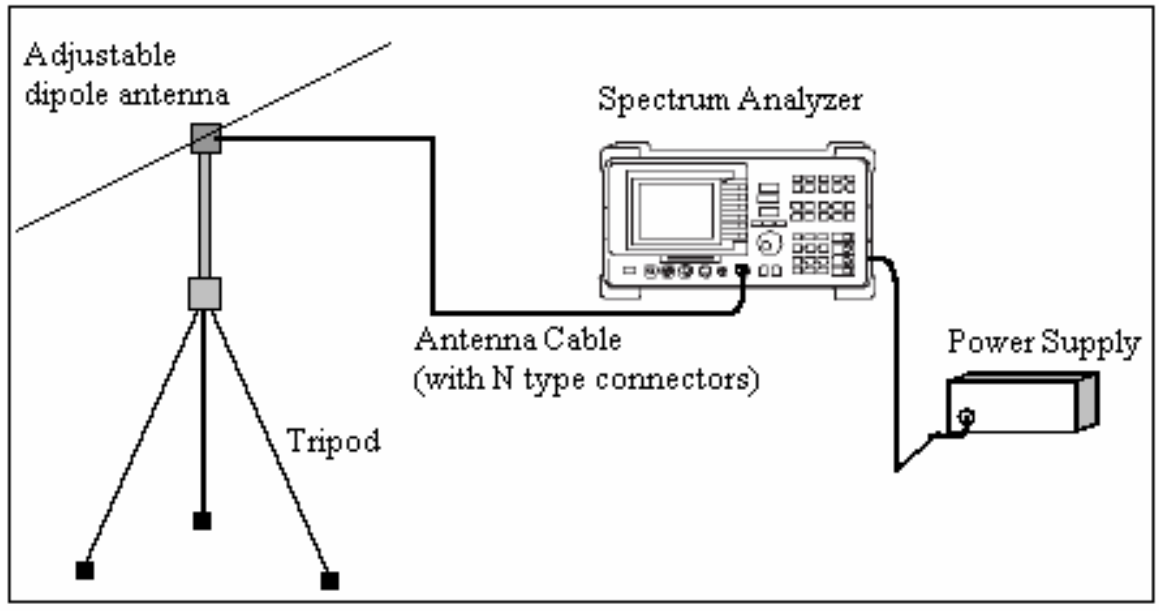

Figure 1: Measurement set-up

The antenna was mounted $1.4 \mathrm{~m}$ above the ground level and the antenna length was adjusted to a half-wavelength with respect to the frequency ${ }^{10}$. The maximum received voltage; $V_{m}$ in $\mathrm{dB} \mu \mathrm{V}$, was obtained from the spectrum analyzer, by rotating the antenna. This was repeated for all transmitters operating at different frequencies of FM radio, Television and Cellular Mobile Base stations. A typical spectrum analyzer measurement is shown in Figure 2. 


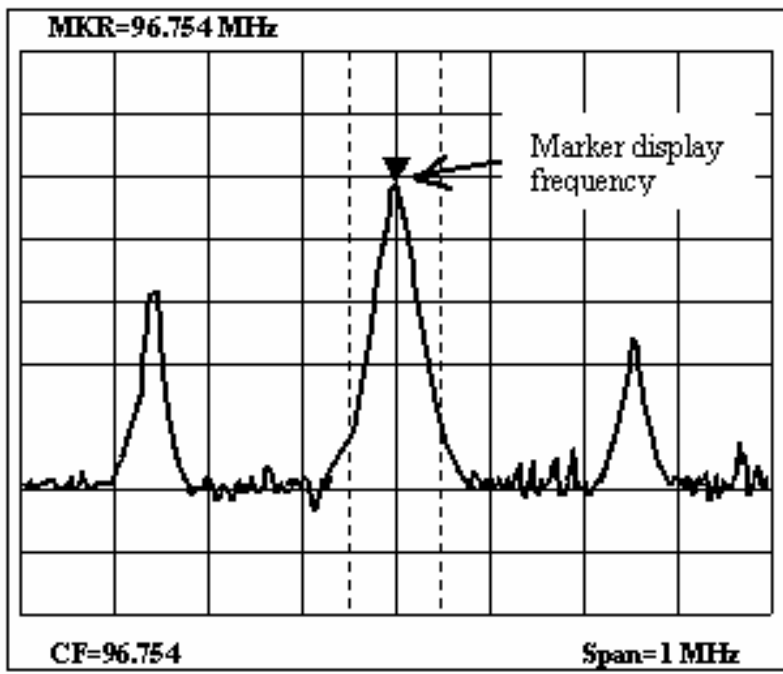

Figure 2: Spectrum analyzer measurement of FM radio broadcast signal.

The measured value of $V_{m}$ was converted to field intensity $E(\mathrm{~V} / \mathrm{m})$ using equation(7).

$E(\mathrm{~dB} \mu \mathrm{V} / \mathrm{m})=K(\mathrm{~dB} / \mathrm{m})+V_{m}(\mathrm{~dB} \mu \mathrm{V})+L(\mathrm{~dB})$

where $K(\mathrm{~dB} / \mathrm{m})$ is the antenna factor which is the ratio of electric field strength at antenna to the voltage produced at antenna connector and $L(\mathrm{~dB})$ is the total system loss. The system loss was measured experimentally using a synthesized signal generator and it was observed that $L=8 \mathrm{~dB} \mu \mathrm{V}$. The value of $K$ is given by the antenna manufacturer ${ }^{10}$.

This signal is only from one direction and it is in the direction of maximum received signal. For the worst case situation we suppose that this field comes from three orthogonal directions ${ }^{8}$. Hence,

$E_{\text {Worst }}^{2}=E_{X}^{2}+E_{Y}^{2}+E_{Z}^{2} ; E_{X}=E_{Y}=E_{Z}=E_{\text {Max }}$

Therefore, $E_{\text {Worst }}(\mathrm{V} / \mathrm{m})=\sqrt{3} E_{\text {Max }}$

From equation (1), the power density in worst-case situation becomes,

$S_{\text {Worst }}\left(\mathrm{W} / \mathrm{m}^{2}\right)=\frac{E_{\text {Worst }}^{2}}{\eta}$

The Electric field strength and the Power density were calculated using equations (7) to (9). All measurements were taken during daytime when most of the mobile phones are 
normally in use and also when FM radio and television broadcasting is going on. The calculated values of field intensity and power density were compared with FCC electromagnetic radiation reference standards given in Table 1.

The estimated maximum electric field intensity and power density at a few selected sites are given in Table 2 .

Table 2: Estimated maximum $E \& S$ values with respect to the center frequency of the received signal for different locations

\begin{tabular}{|c|c|c|c|c|}
\hline Location & Source & $\begin{array}{l}\text { Center Frequency } \\
(\mathrm{MHz})\end{array}$ & $\begin{array}{c}E \\
(\mathrm{~dB} \mu \mathrm{V} / \mathrm{m})\end{array}$ & $\begin{array}{c}S \\
\left(\mu \mathrm{W} / \mathrm{m}^{2}\right)\end{array}$ \\
\hline \multirow{3}{*}{$\begin{array}{l}\text { Colombo Fort } \\
\text { Railway } \\
\text { Station }\end{array}$} & FM radio & 96.754 & 102.04 & 42.428 \\
\hline & Television & 487.35 & 88.1 & 1.712 \\
\hline & Mobile Base Station & 871.0837 & 93.11 & 5.428 \\
\hline \multirow{3}{*}{ Kandy } & FM radio & 91.208 & 75.01 & 0.084 \\
\hline & Television & 170.48 & 72.61 & 0.048 \\
\hline & Mobile Base Station & 955.198 & 78.51 & 0.188 \\
\hline \multirow{3}{*}{ Galle } & FM radio & 100.736 & 55.92 & 0.001 \\
\hline & Television & 511.62 & 64.42 & 0.007 \\
\hline & Mobile Base Station & 955.410 & 102.44 & 46.522 \\
\hline \multirow{3}{*}{ Nuwara-Eliya } & FM radio & 104.200 & 77.12 & 0.136 \\
\hline & Television & 175.10 & 99.03 & 21.216 \\
\hline & Mobile Base Station & 870.628 & 77.40 & 0.146 \\
\hline
\end{tabular}

Table 3 shows the exposure levels from different services.

The values in Table 3 show the maximum possible exposure levels because these results are based on the worst-case condition and they are well below the FCC guidelines. The highlighted values are of particular interest and are considered for discussion. 
Table 3: Contribution to the total exposure due to FM radio, TV and Cellular Mobile base stations.

\begin{tabular}{|c|c|c|c|c|c|}
\hline City & $\sum_{i=1}^{\mathrm{FM}} \frac{S_{i}}{M P E_{i}}$ & $\sum_{i=1}^{n 2} \frac{S_{i}}{M P E_{i}}$ & $\begin{array}{l}\text { Base } \\
\text { Stations } \\
\sum_{i=1}^{n 3} \frac{S_{i}}{M P E_{i}}\end{array}$ & $\sum_{i=1}^{\text {Total }} \frac{S_{i}}{M P E_{i}}$ & $\begin{array}{l}\text { TBL } \\
\frac{1}{\sum_{i=1}^{n} \frac{S_{i}}{M P E_{i}}}\end{array}$ \\
\hline Colombo Fort & $1.30 \times 10^{-3}$ & $1.89 \times 10^{-5}$ & $9.52 \times 10^{-5}$ & $1.40 \times 10^{-3}$ & 714.29 \\
\hline Kandy & $1.13 \times 10^{-6}$ & $1.62 \times 10^{-6}$ & $2.06 \times 10^{-6}$ & $4.80 \times 10^{-6}$ & $2.08 \times 10^{5}$ \\
\hline Gampaha & $2.45 \times 10^{-7}$ & $2.23 \times 10^{-7}$ & $2.12 \times 10^{-5}$ & $2.16 \times 10^{-5}$ & $4.62 \times 10^{4}$ \\
\hline Matara & $3.58 \times 10^{-8}$ & $2.89 \times 10^{-7}$ & $3.21 \times 10^{-5}$ & $3.24 \times 10^{-5}$ & $3.08 \times 10^{4}$ \\
\hline Galle & $6.17 \times 10^{-8}$ & $9.10 \times 10^{-8}$ & $1.49 \times 10^{-4}$ & $1.49 \times 10^{-4}$ & $6.69 \times 10^{3}$ \\
\hline Nuwara-Eliya & $4.51 \times 10^{-6}$ & $3.93 \times 10^{-4}$ & $4.75 \times 10^{-6}$ & $4.02 \times 10^{-4}$ & $2.49 \times 10^{3}$ \\
\hline Kurunegala & $2.48 \times 10^{-8}$ & $1.97 \times 10^{-7}$ & $2.35 \times 10^{-6}$ & $2.57 \times 10^{-6}$ & $3.89 \times 10^{5}$ \\
\hline Kegalle & $7.42 \times 10^{-6}$ & $2.81 \times 10^{-5}$ & $2.83 \times 10^{-5}$ & $6.39 \times 10^{-5}$ & $1.56 \times 10^{4}$ \\
\hline Moratuwa Uni. & $3.95 \times 10^{-7}$ & $3.01 \times 10^{-6}$ & $1.02 \times 10^{-4}$ & $1.06 \times 10^{-4}$ & $9.44 \times 10^{3}$ \\
\hline Colombo Uni. & $9.71 \times 10^{-5}$ & $1.57 \times 10^{-4}$ & $9.18 \times 10^{-6}$ & $2.63 \times 10^{-4}$ & $3.80 \times 10^{3}$ \\
\hline Kuliyapitiya & $9.55 \times 10^{-8}$ & $7.70 \times 10^{-7}$ & $4.68 \times 10^{-8}$ & $9.13 \times 10^{-7}$ & $1.10 \times 10^{6}$ \\
\hline Ambalangoda & $1.13 \times 10^{-8}$ & $1.37 \times 10^{-7}$ & $3.56 \times 10^{-6}$ & $3.71 \times 10^{-6}$ & $2.69 \times 10^{5}$ \\
\hline
\end{tabular}

$n 1, n 2, n 3 \& n$ are the number of transmitters of FM, TV and Mobile base stations respectively.

Among the locations considered, the highest exposure level is at Colombo Fort Railway station and measurements were taken at a place close to the car park of the railway station. The highest contribution to RF absorption by the human body at this site is due to FM radio broadcasting. However the exposure level is approximately 1/715 times the accepted limits. In other words, the exposure level is $0.14 \%$ of the acceptable level and therefore it is much less than the specified limits. Fig: 3(a) shows the relative effects at the Colombo site.

From Table 3, it also appears that in many of the places, the contribution to the exposure levels from cellular mobile base stations is the most significant. For example, Kandy, Gampaha, Matara, Galle and Kurunegala; Fig:3(b), (c), (d), (e) and (g). The exceptions are the sites at Colombo Fort, Nuwara-Eliya, Colombo University premises and Kuliyapitiya. 
In most populated areas such as Colombo Fort, the cellular operators have built micro cellular base stations within short distances thereby reducing the transmitter power. This may be the cause of low RF radiation from cellular mobile base stations in the Colombo Fort area.

Our results indicate that the highest effect of exposure to RF radiation in Nuwara-Eliya Fig:3(f) is due to TV broadcasting antennas. This is understandable because most of the high power TV transmitters for island wide transmission are located in this part of the country. That means, the effect due to cellular base stations in this region is relatively low. In Kandy and Kegalla, the contributions to RF radiation exposure due to FM radio, TV and Cellular Base stations appear to be roughly the same, Fig:3(b) and (h).

\subsection{Compliance distances}

Compliance distances with respect to many transmitters were calculated using equation (6) using technical data ${ }^{9}$ as at July 2004. A total of 44 base stations located within $15 \mathrm{~km}$ from Moratuwa University premises as given in Table 4 were taken into consideration for this calculation:

Table 4: Base Stations around Moratuwa University

\begin{tabular}{|l|c|}
\hline Network & $\begin{array}{l}\text { Number of } \\
\text { base stations }\end{array}$ \\
\hline Dialog GSM & 10 \\
\hline Mobitel & 7 \\
\hline Celltel Analog & 3 \\
\hline Celltel GSM & 10 \\
\hline Lanka Cellular Analog & 7 \\
\hline Lanka Cellular GSM & 7 \\
\hline
\end{tabular}




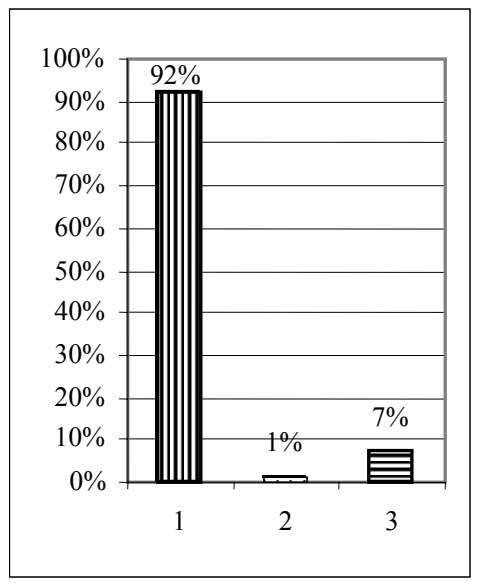

(a). Colombo Fort Railway Station

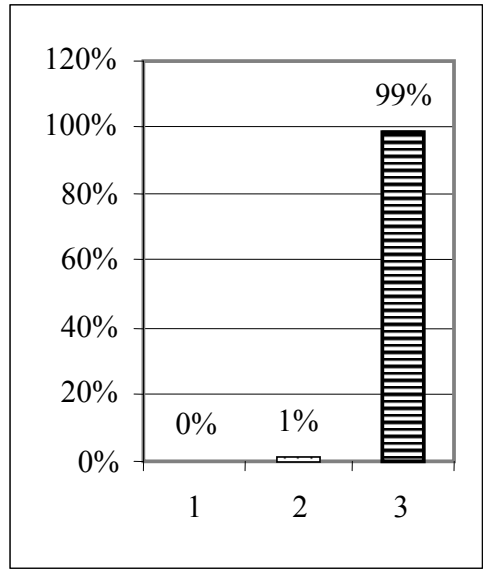

(d). Matara

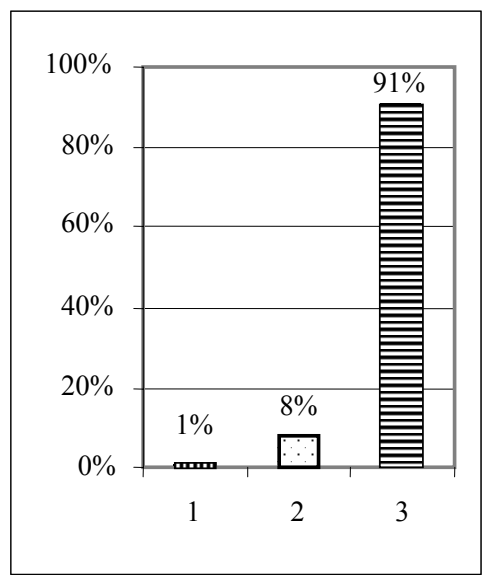

(g). Kurunegala

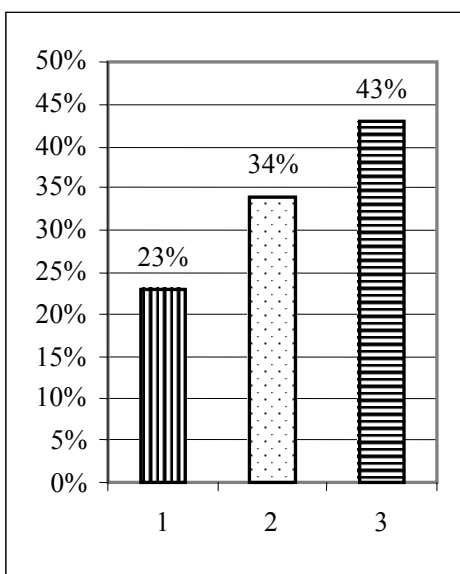

(b). Kandy

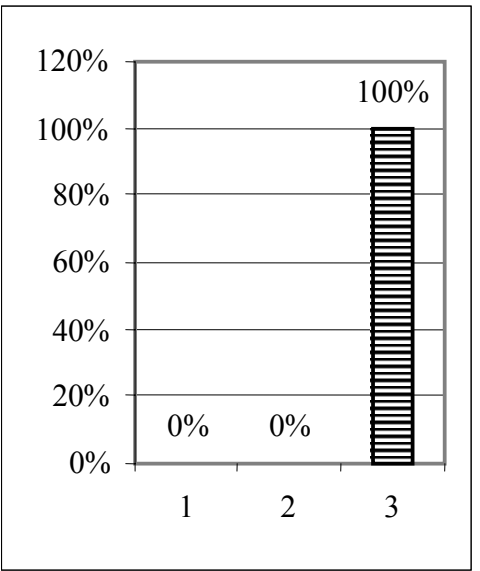

(e). Galle

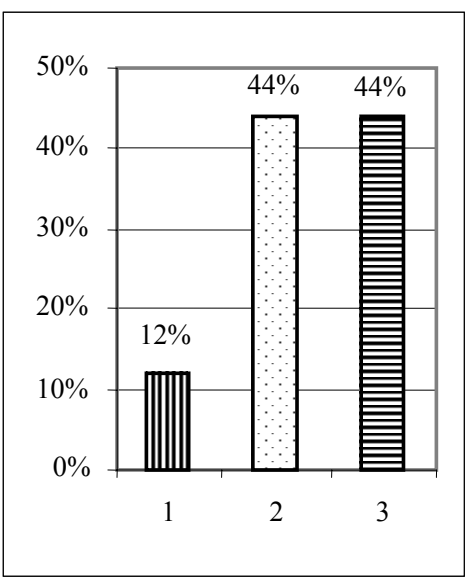

(h). Kegalla

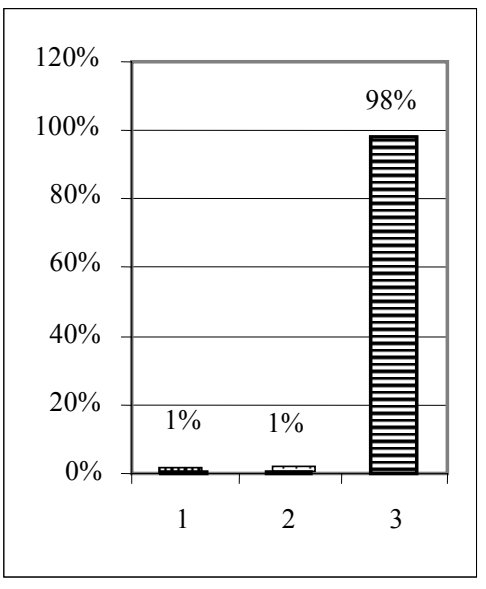

(c). Gampaha

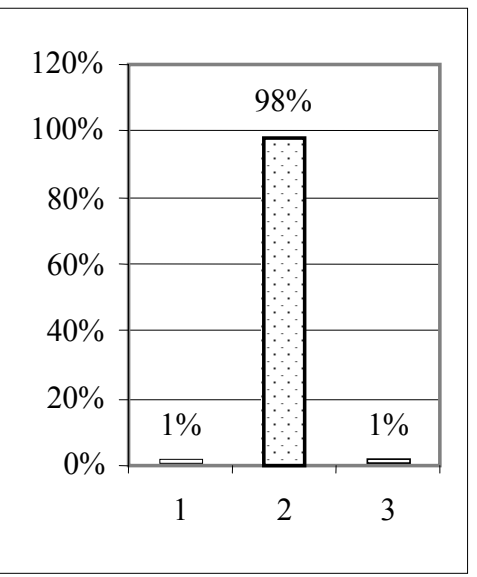

(f). Nuwara-Eliya

Legend:

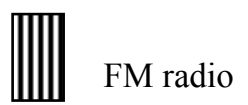

Cellular Mobile

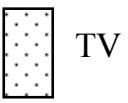

Figure 3: Exposure due to different services as a percentage for different topologies:- (a) Colombo Fort Railway Station (b) Kandy (c) Gampaha (d) Matara (e) Galle (f) Nuwara Eliya (g) Kurunegala (h) Kegalle 


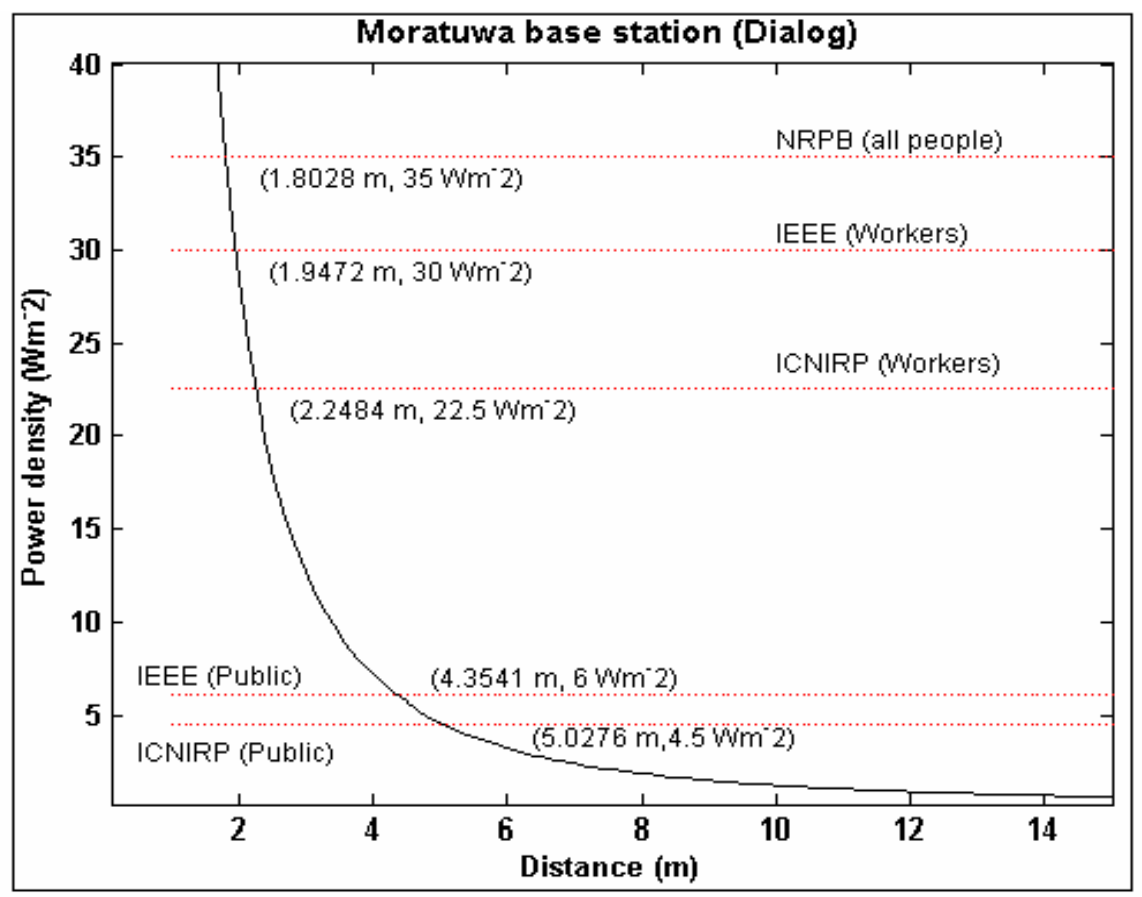

Figure 4: The compliance distances according to different standards for the 'Dialog GSM' base station antenna at Moratuwa.

The compliance distance for the base station of 'Dialog GSM' at Moratuwa are shown in figure 4. Calculations were made according to IEEE standards, NRPB standards and ICNIRP standards.

According to IEEE standards specified for the general public, the safe distance is approximately $4.35 \mathrm{~m}$ from the antenna. Table 5 gives the locations of the base stations, with the estimated maximum compliance distances for each operator. The most restricted guidelines ICNIRP (General public) ${ }^{4}$ was taken as the standards.

Table 5: Shows the maximum compliance distances for different operators.

\begin{tabular}{|l|c|l|}
\hline Operator & $\begin{array}{l}\text { Maximum Compliance } \\
\text { distance (m) }\end{array}$ & $\begin{array}{l}\text { Location of the } \\
\text { base station }\end{array}$ \\
\hline Lanka Cellular & 8.7 & Ratmalana \\
\hline Celltel & 6.7 & Moratuwa \\
\hline Mobitel & 17.1 & Maharagama \\
\hline Dialog & 9.8 & Kesbewa \\
\hline
\end{tabular}


According to the calculations, the base station at Maharagama has the maximum compliance distance of $17.1 \mathrm{~m}$. In other words we have to be at a distance of $17.1 \mathrm{~m}$ from the antenna for safety.

When considering the heights at which antennas are mounted and the slight downward tilt of the antennas, the main beam from base station antennas are expected to reach ground level typically between 50 and $300 \mathrm{~m}$ from the foot of the antenna mast. Therefore, close to the foot of the mast, the exposure levels are very low. Typically the power in the antenna minor lobes which may be directed downwards is at least a hundred times weaker than the power in the main beam. The compliance distances are very useful for the people living in the vicinity of the cellular base station. For the people living in the buildings at the same height of these antennas, the compliance distance is a direct distance for consideration as the safety distance.

\section{CONCLUSIONS}

Measurements indicate that the exposure levels due to all services as at July 2004 for the general public at locations considered in this work are well below FCC specified safety standards. Hence the radiating antennas are not a threat for public health. As the antenna main beam would reach ground level at a distance of approximately $50 \mathrm{~m}$ from the bottom of the antenna mast, the radiation level up to about $50 \mathrm{~m}$ is only due to any minor lobes and this is expected to be extremely small and therefore will not be a threat to public health.

\section{ACKNOWLEDGEMENTS}

The authors are grateful to the TRC for providing the necessary data for calculations. 


\section{REFERENCES}

1. James C.Lin, Biological Bases of Current Guidelines for Human Exposure to Radio-Frequency Radiation, IEEE Antennas and Propagation Magazine, Vol.45, No.3, June 2003.

2. FCC Std.,Guidelines for Evaluating the Environmental Effects of Radio Frequency Radiation, FCC 96-326, Washington,DC,1996.

3. IEEE Std. C95.1-1999, IEEE Standard for Safety Levels with Respect to Human Exposure to Radio Frequency Electromagnetic Fields, $3 \mathrm{kHz}$ to $300 \mathrm{GHz}$, Institute of Electrical and Electronic Engineers, Inc., New York, 1999.

4. ICNIRP Std., Guidelines for Limiting Exposure to Time-varying Electric, Magnetic and electromagnetic Fields (Up to 300GHz), Health Physics, 74, 1998,pp.494-522.

5. S.M. Mann, T.G. Cooper, S.G. Allen, R.P. Blackwell and A.J. Lowe, Exposure to Radio Waves near mobile Phone Base Stations, NRPB-R321, June 2000.

6. R.C. Petersen, P.A. Testagrosa, Radio frequency electromagnetic fields associated with cellular radio cell-site antennas, Bioelectromagnetics ; 1992; 13 : 527-42.

7. C.Arnelli, G. Roggia and D.Trinchero, Low Cost Measuring Methods Applied to an Electromagnetic Site Survey of a Complex Environment, $29^{\text {th }}$ Europeean Microwave Conference, Munrich, 5-7 Octomber 1999.

8. Greek Common Ministerial Decree, Protection measures for the exposure of the general public to all land based antenna station, Act. No 1105/Vol.B/ 06-09-2000.

9. Consultation document, Radio Frequency spectrum allocations of Sri Lanka, Telecommunications Regulatory Commission of Sri Lanka (TRCSL)/2004; www.trc.lk

10. Catalog of EMCO's model $3121 \mathrm{C}$ tuned dipole antenna, Antenna gain and antenna factors, ETS manufactures/ www.ets-lindgren.com 